\title{
Anomalies of precipitation and drought in objectively derived climate regions of Iran
}

\author{
SонrAв GHAEDI ${ }^{1}$
}

\begin{abstract}
By regionalizing precipitation in 113 synoptic stations in Iran, the characteristics of precipitations and the occurrence of droughts in each region were investigated over a period of 30 years, 1988-2017. Elevation, latitude and distance from moisture source have caused strong East-West and South-North gradients of precipitation across the territory of Iran so that the average annual precipitation increases from $55 \mathrm{~mm}$ in the eastern and central regions to $1,730 \mathrm{~mm}$ in the south-west coast of the Caspian Sea. Hierarchical cluster analysis identified six precipitation regions in Iran, including the arid, semi-arid, moderate, semi-humid, humid, and high humid regions. An investigation of the standardized precipitation index (SPI) showed that the trend in about 19 per cent of stations was significantly decreasing. It was non-significantly decreasing in 65 per cent, significantly increasing in less than 1 per cent, and non-significantly increasing in 15 per cent of the stations. While the occurrence of drought has increased in most parts of Iran, it has decreased in some stations only in the northern strip of the country. The line slope in more than 84 per cent of the stations represent negative values in SPI, which confirms an increase in the occurrence of droughts in Iran.
\end{abstract}

Keywords: hierarchical cluster analysis, anomaly of precipitation, drought trend, Iran

Received February 2021, accepted May 2021

\section{Introduction}

Natural environmental conditions have a great impact on the economic and social infrastructure of human societies, and climate is one of the most important factors in this regard. The role of precipitation in climatic conditions is very vital due to the supply of required water resources. Although precipitation is a complex and highly variable element, climate change has increased its variability. Climate change means a change in the average climate or its variability over an extended period. With an increase in greenhouse gas emissions in recent decades, climate change has become known as increasing temperatures and consequently global warming. Although climate change includes all climatic conditions, changes in temperature and precipitation are more evident. Many climate change studies have indicated that annual rainfall in the subtropical regions may lead to decrease in the current century (DAI, A. et al. 2018). Meteorological drought is a persistent decrease in precipitation below the average in a region over a period of time (DAI A. 2011; HAO, Z. and Singh, V.P. 2015; Gulácsi, A. and KovÁcs, F. 2018). The occurrence of droughts has influenced the availability of water resources (SzABó, S. et al. 2019), especially in water-limited regions. Reduced availability of water resources affects all aspects of human life, such as the environment, agriculture and food security, and it can cause significant losses to human societies (SomorowsKA, U. 2017).

Iran is a dry land territory that mainly receives very little rainfall (GHAedi, S. and Shojaiean, A. 2020). Under the influence of the Azores high-pressure subtropical system, precipitation is close to zero in most parts of

\footnotetext{
${ }^{1}$ Shahid Chamran University of Ahvaz, Ahvaz, Iran. E-mails: s.ghaedi@scu.ac.ir, or sohrabghaedi@gmail.com ORCID: 0000-0001-5922-0604
} 
the country during the warm period of the year (GHAEDI, S. 2021). Low rainfall has led to the formation of very large deserts in the East (the Kavir and Lut deserts) and in the South of the country with less than $100 \mathrm{~mm}$ of rainfall. Iran's population has increased from about 22 million in 1960 to more than 83 million in 2020. An increase of about 400 per cent in the population in the last 60 years has increased the need for drinking water, and industrial and agricultural projects. The purpose of building large dams in Iran is to store water resources gathered in rainy periods for periods of low rainfall. However, these dams also create problems for downstream water supply and dry up wetlands and lakes. Evaporation from the surface of lakes behind the dams is very high in hot regions such as Iran and causes a waste of abundant water resources. Due to an increasing temperature trend in most stations of Iran (ZAREI, A.R. and Masoudi, M. 2019), the rate of evaporation from these lakes has also increased over the time. The use of groundwater resources has also increased significantly in the last few decades (DARIJANi, F. et al. 2019), and the rate of abstraction has been much higher than the rate of water infiltration into the deeper layers. Overall, global warming, severe rainfall anomalies, persistent droughts, growing population, and, most importantly, weakness in the management of water resources have put a lot of pressure on water resources (NourI, M. and Homaee, M. 2020).

A number of studies have investigated the anomaly of precipitations and droughts in Iran from different aspects. Some have focused on specific regions (TABARI, H. et al. 2012; Rostamian, R. et al. 2013; Zarei, A.R. et al. 2016; ZAREI, A.R. 2018; ZAREI, A.R. and Masoudi, M. 2019; Moghbeli, A. et al. 2020). Others have investigated sub-regions with distinct climatic conditions, impact on the environment and agriculture (DANESHVAR, M.R.M. et al. 2013; Aliabad, F.A. and Shojaei, S. 2019), and impact of climate change (KHAJEH, S. et al. 2017). Further studies have covered the whole country with a limited number of stations (Abarghouei, H.B. et al. 2011; Amirataee, B. and Montaseri, M. 2017; Nouri, M. and
Homaee, M. 2020), while others have dealt with drought risk assessment (DANESHMAND, H. and Mahmoudi, P. 2017; Sharafi, L. et al. 2020), and modelling, prediction and trend assessment of drought (ModArRes, R. et al. 2016; BAHRAMI, M. et al. 2019).

In the present paper, the precipitation regions of Iran were first zoned using the average annual precipitation. Then, the anomaly of precipitations and meteorological droughts were studied in the precipitationbased regions.

\section{Data and methods}

This study investigated anomalies of precipitation and droughts over Iran. With an area of $1,648,195 \mathrm{~km}^{2}$, Iran is a relatively large territory in South-west Asia, located between approximately $25^{\circ} \mathrm{N}$ and $40^{\circ} \mathrm{N}$ and $45^{\circ} \mathrm{E}$ and $64^{\circ} \mathrm{E}$. The main humid sources of precipitation in Iran are the western (Mediterranean cyclones) and south-western (Red Sea trough) systems in the cold season and the south-eastern (Gang low pressure) system in the warm season (Degirmendžić, J. and KożUchowsKI, K. 2017). The Zagros Mountains in the West and the Alborz Mountains in the North, as well, as other vast water bodies (i.e. the Persian Gulf and the Oman Sea in the South and the Caspian Sea in the North) have caused a great deal of spatial climatic diversity in Iran.

\section{Data}

The first meteorological station in Iran was established in 1929. After that, the main stations at provincial centres have been recording meteorological data since 1950 . To apply data in climatological studies, in addition to the statistical period, it is necessary to pay attention to the area of the region, the variety of topography, and the climatic conditions in the proportional distribution of stations in the region under study (GHAEDI, S. 2019). In this study, monthly precipitation data of 113 stations were used for the period 1988-2017 (Figure 1). 


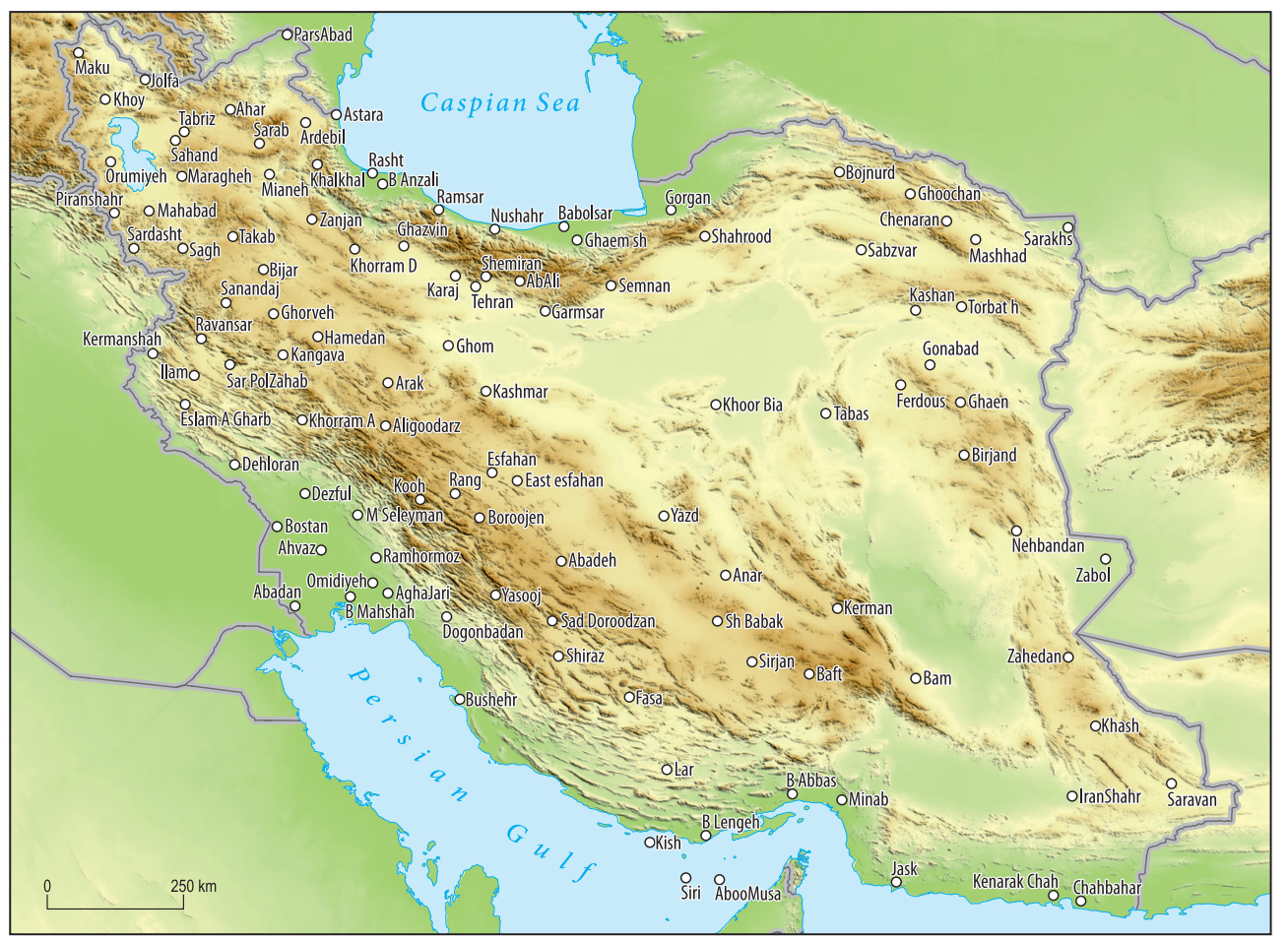

Fig. 1. Digital elevation model (DEM) of the study area and location of the synoptic stations

\section{Methods}

A hierarchical cluster analysis was performed to regionalize the annual precipitations in the meteorological stations of Iran, which had data for the whole 30 years. Based on the agglomerative multivariate statistical technique of cluster analysis, datasets and/ or large amounts of decreasing data are classified into subgroups or dendrograms, which make different possible groups easily visible and manageable (FAzEL, N. et al. 2018). It is assumed that if there is a precipitation gradient in the region, differentiated clusters following different geographical directions can be obtained from this analysis. Initially, a dissimilarity matrix is created. Then, each object is placed in a special cluster. After that, based on the distance matrix, two similar objects are joined together, and this operation continues until a single cluster is created. There are dif- ferent methods for data linking, but due to the fact that in many climatological studies, Ward's linkage has been considered as an appropriate one, this technique was used in the current study. To calculate the distance matrix, the Euclidean distance method was used. The number of clusters is determined by the researcher, and the number of acceptable and fairly homogeneous clusters can be obtained by varying the number of clusters. The silhouette width method was used to assess the homogeneity of the clusters, i.e. the clusters' quality (Lengyel, A. and BottaDukÁt, Z. 2019). This graphical method helps to interpret the clusters. The purpose of this is to assess the accuracy of the placement of objects in their cluster and to check whether it is possible to change the cluster of an object.

Several indices have been developed in recent decades to determine the severity and duration of droughts. McKEE, T.B. et al. (1993) 
proposed and developed the standardized precipitation index (SPI), which is currently one of the most widely-used indices to quantify meteorological drought. SPI determines periods of positive or negative precipitation anomalies over a given region using precipitation data for a selected timescale. Simply, meteorological drought is the strong decrease in precipitation over a period of time in a specific region relative to the long-term average precipitation of that region. Finally, this difference is standardized by dividing it by standard deviation (Amirataee, B. and Montaseri, M. 2017) (see Eq. 1).

$$
S P I_{i}=\frac{P_{i}-\vec{P}}{\delta},
$$

where $S P I_{i}$ represents the drought index, $P_{i}$ is the precipitation value in period $i^{\text {th }}$, and $\bar{P}$ and $\delta$ are the mean of precipitation and standard deviation of precipitation, respectively.

In order to accurately assess drought indices and to determine dry and wet periods, a classification including seven categories of extreme drought (-2 or less), severe drought (-1.99 to $-1.50)$, moderate drought (-1.49 to -1.00$)$, mild drought (-0.99 to 0$)$, mild wet (0 to 0.99$)$, moderate wet (1.00 to 1.49$)$, very wet (1.50 to 1.99$)$, and extreme wet (2.00 or more) was presented.

Continuous meteorological drought leads to hydrological drought and, as a result, surface water resources (rivers, lakes, etc.) and groundwater levels are significantly decreased.

Parametric and non-parametric methods can be used to determine significant trends in climatologic time series. Non-parametric trend tests require data to be independent, while parametric trend tests in addition require that the data be independent they must have a normal distribution. Mann-Kendall and Sen's slope estimator as two non-parametric methods were used to detect the meteorological variables' trends in this study.

The Mann-Kendall (MK) test was used to calculate precipitation and drought trends during the study period. Based on this nonparametric method, if the standard normal test statistic ( $Z$ parameter) at 95 per cent confi- dence level is more or less than 1.96/-1.96, it indicates a significant increase/decrease in time series, respectively. If the $Z$ value is between 0 and 1.96, the increase is non-significant, and if it is between 0 and -1.96, it indicates a nonsignificant decrease in the data trend.

The Mann-Kendall test only determines the trend and its direction, but it does not show the magnitude of the trend line. Therefore, the Sen's slope estimator technique (reference, please) is used to determine the numerical value of the line slope along with the MannKendall method. This non-parametric method involves computing slopes for all the pairs of ordinal time points by applying the median of these slopes as an estimate of the overall slope.

\section{Results and discussion}

\section{The annual precipitation}

The average annual map of precipitation (Figure 2) shows that precipitation across Iran varies with the highest values in the northern and the lowest values in the eastern and central regions. According to Figure 2, precipitation surfaces for each year for the period 1988-2017 show that there is also variability in the pattern of precipitation across Iran between the years.

\section{Regionalization by cluster analysis}

The survey of precipitation surfaces in each of the years of the study period illustrates that there is intense variability in the precipitation pattern of all regions of Iran. However, the north-south and West-East gradients persist throughout the year, the spatial distribution of precipitation changes from year to year. According to precipitations in all stations in the study period, in the years 1991, 1992, 1993, 1994, 1996 and 2004, the rainfall was more than the third quarter and in the years 1990, 2000, 2001, 2008, 2010, 2013 and 2017, it was less than the first quarter.

Cluster analysis and the resulting dendrogram chart demonstrated that six clus- 


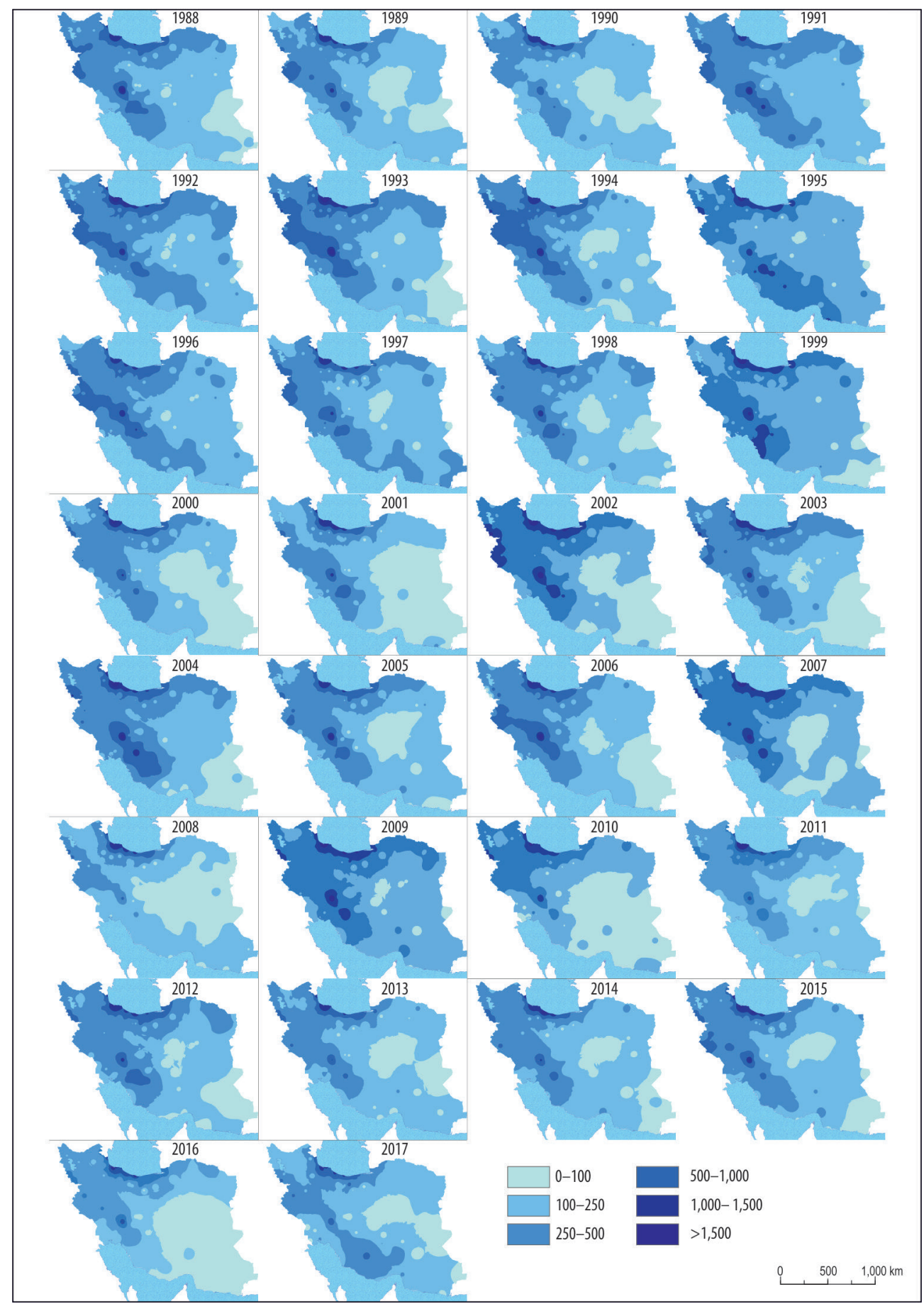

Fig. 2. The average annual precipitation (mm) for each year (1988-2017) across the studied region 
ters could be identified at the stations in the studied period. The cluster spatial distribution is presented in Figure 3, and, as is hypothesized, the resulting groups follow the precipitation gradient across the region.

Clusters A to F are the driest to the wettest precipitation regions of Iran, which can be called arid, semi-arid, moderate, semi-humid, humid and high humid, respectively. The study of the spatial distribution of clusters indicates that the three factors of elevation, latitude and distance from the large water bodies, especially from the Caspian Sea, determine the resulted clusters. The wettest clusters are related to the south-western shores of the Caspian Sea (E and F) and to the heights of the Alborz and Zagros mountains (C and D). All regions of the eastern half of the country, except the heights of the northern regions and a small area in the South (Lalehzar Mountain), include the arid parts of Iran (A). Low altitude, distance from western moisture sources (the Mediterranean Sea and the Red Sea) and being located in the lee side of the Alborz and Zagros heights have decreased rainfall in these regions. In the margins of arid and foothill areas, semi-arid areas are observed (B). Figure 3 illustrates the average annual precipitation for each cluster in the studied period (1988-2017).

\section{Trend of precipitation}

The results of the Mann-Kendall trend test illustrate that the majority of stations under study decline in the annual precipitation totals for the extended period of 1988-2017, which is consistent with previous studies (Some' $\mathrm{E}$, B.S. et al. 2012; NAJAfi, M.R. and MoAzAmi, S. 2016). From the 113 stations under study, 95 stations

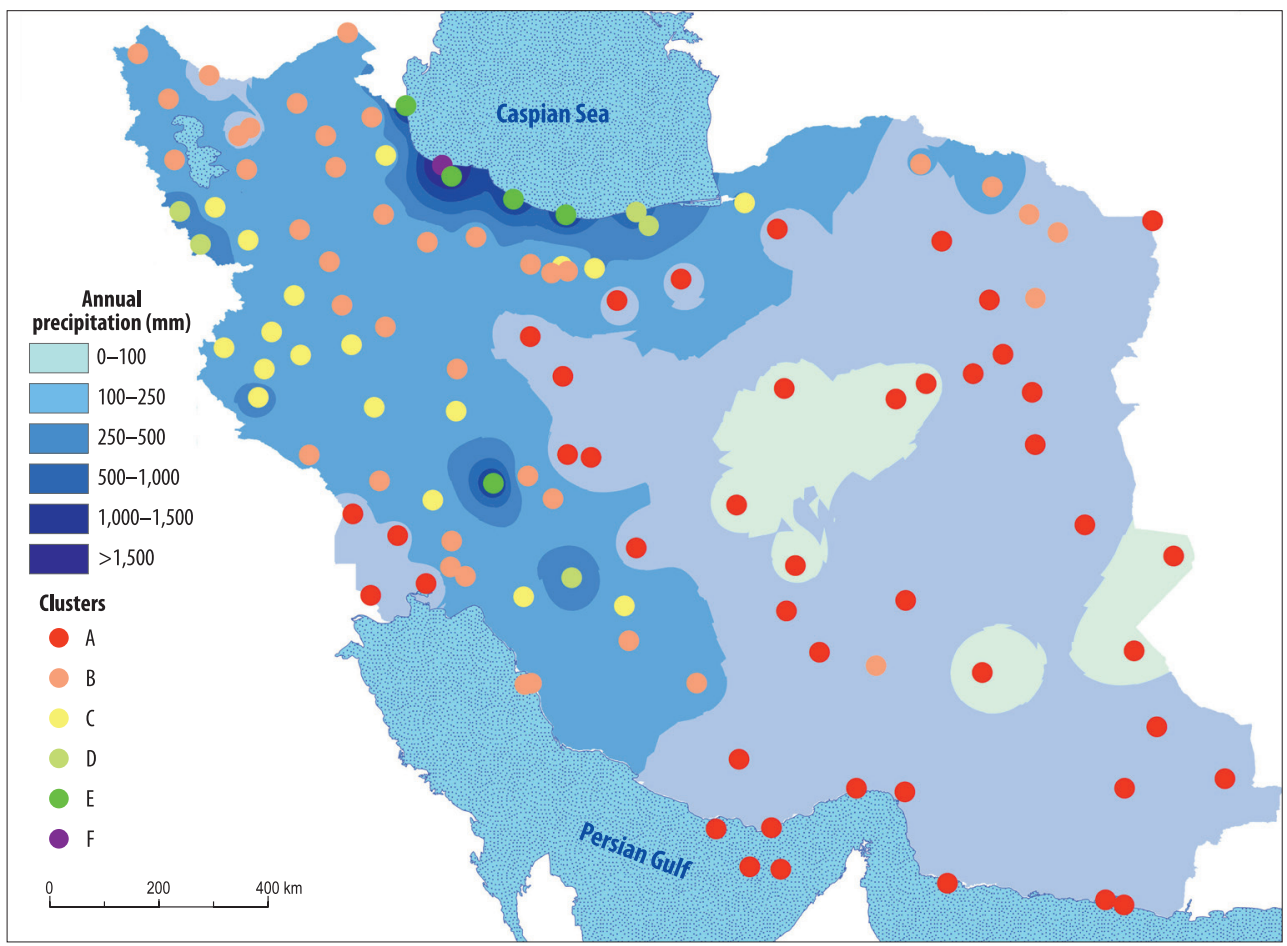

Fig. 3. Annual precipitation average and spatial distribution of clusters (A-F) resulted from the hierarchical cluster analysis 
(84\%) show decreasing trends, among which 21 stations have significant decreases considering a 5 per cent level of significance (Figure 4, left). Significant decreases occur in the East and West of Iran as well as in the central regions of the country and the south-east of the Persian Gulf. Spatial heterogeneity of precipitation trends is due to complex topography or other environmental conditions such as wind direction, the physical condition of the ground surface, topographic direction, water resources, etc. Hence, in some adjacent stations, such as the stations in the North, north-east and south-east, opposite trends have occurred.

Figure 5 represents the average annual precipitation per year for each cluster. Despite the relatively large variability in the point-wise precipitation during the studied 30 years, the

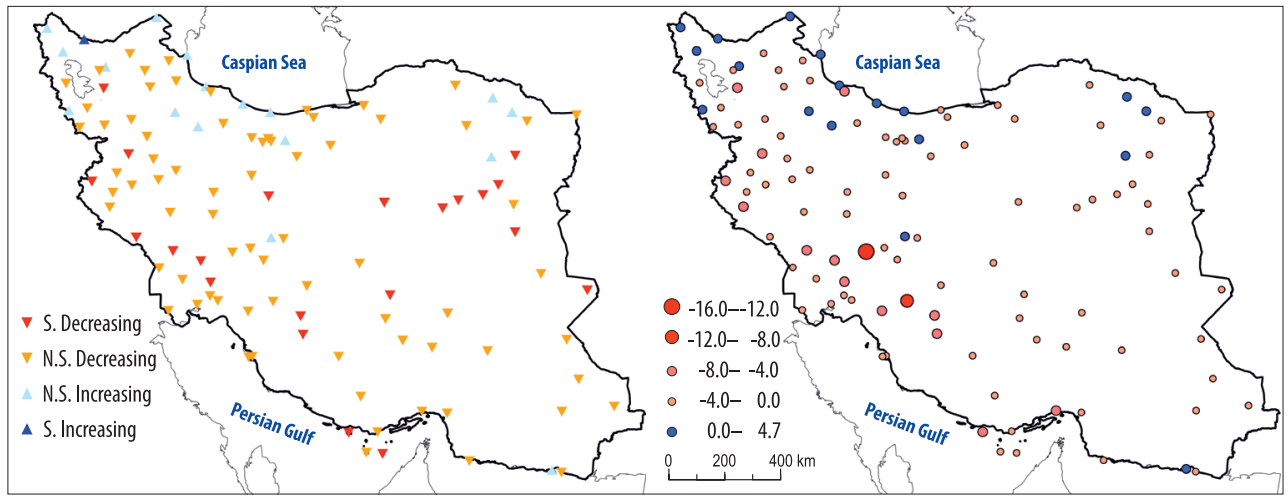

Fig. 4. The annual precipitation trend (left) estimated based on the Mann-Kendall test considering a 5 per cent significance level and Sen's slope estimator of precipitation (right). N.S. means non-significant in the left part of this figure.

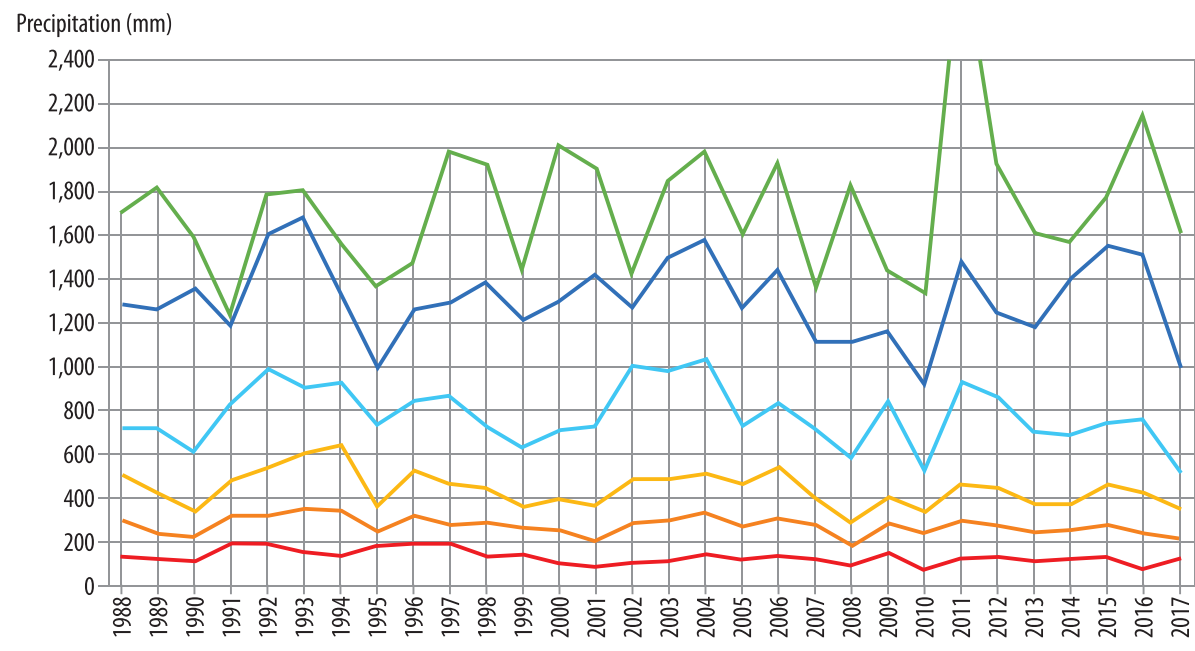

Fig. 5. Mean annual precipitation (mm) totals in clusters A-F, 1988-2017 
interval of precipitation amount averaged for the clusters has been stable among the years, and relative coordination is observed in the precipitation anomalies so that they occur almost simultaneously in all clusters.

\section{Variability of drought events}

The spatial and temporal variability of drought events for the period 1988-2017 is presented in Figure 6 using the SPI method based on a 12-month time step. The most severe droughts were observed in 1990, 2001, 2008, 2010, 2016 and 2017 when many parts of the country experienced mild to severe droughts.

The time series of the SPI for each precipitation clusters are presented in Figure 7. It can be observed that the performance of SPI is almost the same in all precipitation regions. The most severe droughts have occurred in highly humid (cluster F) and semi-humid (cluster D) regions in 1991 and 2017, respectively, and in 2010, 2013 and 2017, when the SPI index was negative in all clusters. Although in these years the SPI index is positive in the limited regions, but the average of all clusters is negative. The severity of the 2010 drought is higher than in 2013 and 2017. Wetter years (1992, 1993 and 1996) can also be identified in these maps. These years were also identified as wetter than average years by DAshtPagerdi, M.M. et al. (2015). Ahmadi, M. et al. (2019) believe that in 1992 and 1993 the composite synoptic patterns includes Pacific: warm, Atlantic: cool and Indian: cool have increased precipitation over Iran.

\section{Trend of droughts}

Figure 8 shows the results of SPI intensity trend based on the application of MannKendall test (left) and its line slope according to Sen's method (right) for the magnitude of the trend. The Mann-Kendall test revealed a significant decreasing trend in SPI in 18.6 per cent and a non-significant one in 65.5 per cent of all regions. In the semi-humid to high humid areas, non-significant decreas- ing trends were observed. The SPI trend was non-significantly increasing (except for Jolfa station in north-western Iran, having a significant increasing trend) for 15 per cent of the surveyed stations, which are mostly situated in the northern strip of Iran (Table 1).

The results obtained from Sen's slope technique (Figure 8, right) illustrate the slope is negative in most stations with its range varying between 0 and -0.073 . In the western and eastern regions, the slope shows larger negative values. In 16 per cent of the stations, which include regions in the northern part of the country and two stations in the centre (Isfahan) and south-east (Kenarak, Chahbahar), the slope is positive.

\section{Conclusions}

This study was conducted to better understand the precipitation anomaly and the occurrence of drought in Iran in each of the precipitation-based regions. The average annual precipitation in Iran varies from $51 \mathrm{~mm}$ in the eastern and central regions to $1,730 \mathrm{~mm}$ in the south-western shores of the Caspian Sea. To gain a more comprehensive insight into precipitation variability, cluster analysis methods were performed. Hierarchical cluster analysis of annual precipitation data of the studied stations showed that six precipitation clusters could be identified in Iran. The clusters from the driest to the wettest regions were named as A to F, respectively. The identified clusters illustrated that the precipitation pattern mostly followed the topography, latitude and distance from humidity sources, i.e. the Caspian Sea, the Red Sea, and the Mediterranean Sea.

In 2010, 2013 and 2017, the SPI index was negative in all clusters, which indicated a widespread drought in all regions of Iran. In some years (1990, 1995, 1999, 2005, 2007 and 2008), drought has occurred in five of the six clusters of precipitation regions of the country. The most severe drought in the period under study is related to 2010 when the SPI index showed large negative numbers in all parts of the country. 


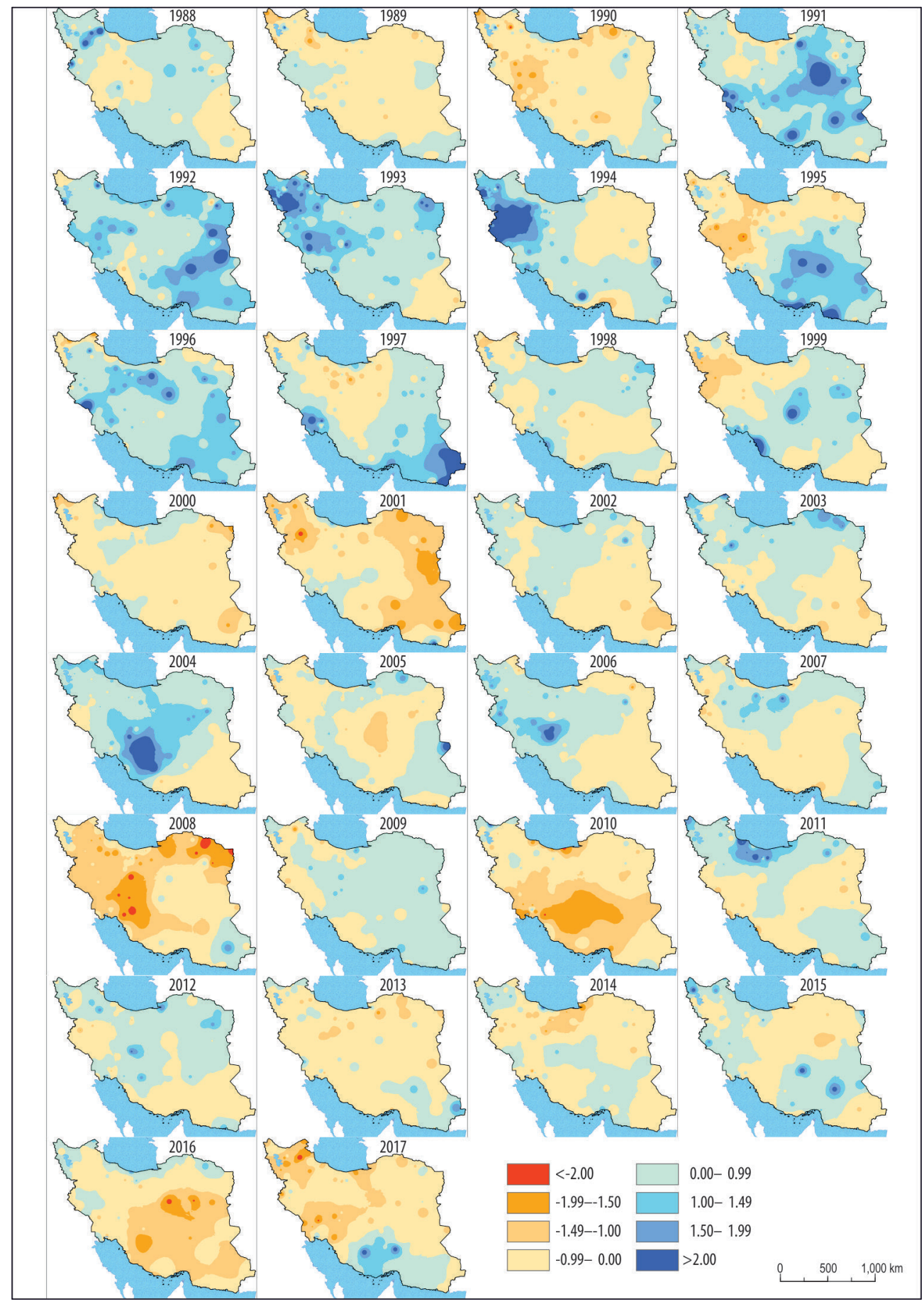

Fig. 6. The 12-monthly SPI values in each year of the studied period 


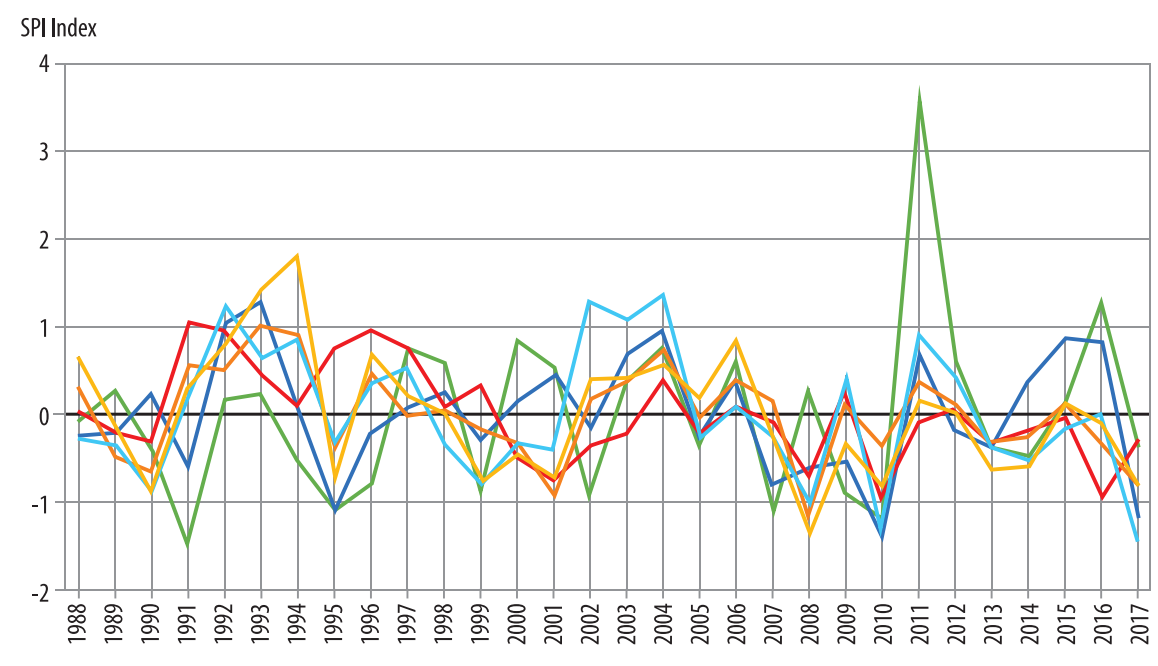

Fig. 7. SPI chart for 12 months in each cluster (A-F) and year, 1988-2017

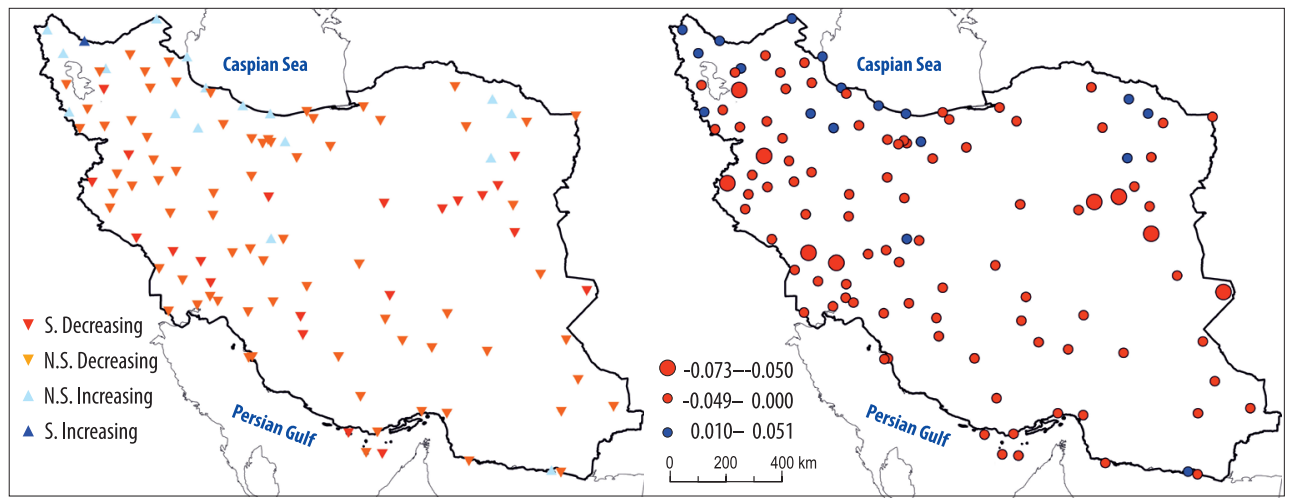

Fig. 8. The annual drought trend (left) estimated based on the Mann-Kendall test considering a 5 per cent significance level and Sen's slope estimator of drought (right)

The significance of linear trends and the line slope for annual series data of total precipitation were tested using Mann-Kendall test and Sen's slope estimator, respectively. An overall decline was observed in the total annual precipitation, particularly in the stations located at latitudes below $36^{\circ} \mathrm{N}$. An overall declining slope was detected in the frequencies of the annual precipitation across Iran. However, a mixture of increasing and decreasing trends in the northern belt of the country was observed.

Table 1 comprehends the properties of precipitation and drought in any clusters. The driest cluster $(\mathrm{A})$ to the wettest cluster $(\mathrm{F})$ can be named as arid, semi-arid, moderate, semihumid, humid and high humid, respectively.

From cluster $\mathrm{A}$ to $\mathrm{F}$, the standard deviations among the clusters (from spatial aspect) have been increasing; therefore, increasing rainfall 
Table 1. Statistics of trend and line slope in the studied station, 1988-2017

\begin{tabular}{|c|c|c|c|c|c|c|}
\hline \multirow{3}{*}{ Clusters } & \multicolumn{4}{|c|}{ Trend } & \multicolumn{2}{|c|}{ Line slope } \\
\hline & \multicolumn{2}{|c|}{ Decreasing } & \multicolumn{2}{|c|}{ Inceasing } & Negative & Positive \\
\hline & S. & N.S. & S. & N.S. & \multicolumn{2}{|c|}{ slope } \\
\hline A & 11 & 30 & - & 3 & 41 & 3 \\
\hline B & 6 & 25 & 1 & 8 & 31 & 9 \\
\hline C & 4 & 13 & - & 1 & 17 & 1 \\
\hline D & - & 4 & - & 1 & 4 & 1 \\
\hline $\mathrm{E}$ & - & 2 & - & 3 & 2 & 3 \\
\hline $\mathrm{F}$ & - & - & _- & 1 & - & 1 \\
\hline$\%$ & 18.6 & 65.5 & 0.9 & 15.0 & 84.0 & 16.0 \\
\hline
\end{tabular}

Table 2. Characteristics of precipitation regions of Iran

\begin{tabular}{l|l|c|c|c|c}
\hline Cluster & \multicolumn{1}{|c|}{$\begin{array}{c}\text { Climate } \\
\text { conditions }\end{array}$} & $\begin{array}{c}\text { Average annual } \\
\text { precipitation }\end{array}$ & $\begin{array}{c}\text { Precipitation } \\
\text { S.D. }\end{array}$ & $\begin{array}{c}\text { No. of drought } \\
\text { years }\end{array}$ & $\begin{array}{c}\text { Mean Sen's } \\
\text { slope }\end{array}$ \\
\hline A & arid & 131.6 & 33.0 & 16 & -1.60 \\
B & semi-arid & 274.5 & 78.5 & 14 & -1.30 \\
C & moderate & 442.0 & 115.0 & 14 & -3.38 \\
D & semi-humid & 777.3 & 181.8 & 16 & -3.14 \\
E & humid & $1,309.0$ & 279.4 & 15 & -2.63 \\
F & high humid & $1,730.0$ & 325.8 & 15 & 4.70 \\
\hline
\end{tabular}

has led to an increase in the standard deviation of the regions (Table 2). With increasing variability in precipitation, the risk of planning increases in the fields of water resources, agriculture and the environment, and, as a result, water resources must be managed more carefully. The number of years of drought occurrence in all clusters is almost equal and varies between 14 years (B and C) and 16 years (A). The line slope values in all clusters except the high humid region are negative, while the highest negative slope $(-3.38)$ is related to the moderate region, and the lowest negative one $(-1.3)$ is related to the semi-arid region. The passage of high pressures formed in northern Iran (August to November) over the warm waters of the Caspian Sea has caused heavy rainfalls, especially on the south-western coast of the sea.

Studies of the water temperature of the Caspian Sea in recent years have shown that the surface temperature of the water has increased significantly (Кноsнакнlagh, F. et al. 2016), which justifies the positive slope of precipitation in the high humid cluster (Anzali port in the south-western part of the Caspian Sea).

The results of this research are in agreement with ZAREI, A.R. (2018), who studied the trends and patterns of drought over the south of Iran and Daneshvar, M.R.M. et al. (2013) that investigated the drought hazard impacts on wheat cultivation in Iran.

The findings of the study on the spatial and temporal variability of precipitation and drought occurrence over Iran are important and useful for the accurate identification of the sub-regions' hydrology and agriculture and for better planning of water resources in all parts of the territory.

\section{REFERENCES}

Abarghouei, H.B., Zarch, M.A.A., Dastorani, M.T., Kousari, M.R. and ZARCH, M.S. 2011. The survey of climatic drought trend in Iran. Stochastic Environmental Research and Risk Assessment 25 (6): 851-853.

Ahmadi, M., Salimi, S., Hosseini, S.A., Poorantiyosh, H. and BAYAT, A. 2019. Iran's precipitation analysis using synoptic modelling of major teleconnection forces (MTF). Dynamics of Atmospheres and Oceans 85. 41-56.

Aliabad, F.A. and Shojaei, S. 2019. The impact of drought and decline in groundwater levels on the spread of sand dunes in the plain in Iran. Sustainable Water Resources Management 5. (2): 541-555.

Amirataee, B. and Montaseri, M. 2017. The performance of SPI and PNPI in analyzing the spatial and temporal trend of dry and wet periods over Iran. Natural Hazards 86. (1): 89-106. 
Bahrami, M., Bazrkar, S. and Zarei, A.R. 2019. Modelling, prediction and trend assessment of drought in Iran using standardized precipitation index. Journal of Water and Climate Change 10. (1): 181-196.

DAI, A. 2011. Drought under global warming: a review. Wiley Interdisciplinary Reviews. Climate Change 2. (1): 45-65.

DAI, A., ZhaO, T. and Chen, J. 2018. Climate change and drought: a precipitation and evaporation perspective. Current Climate Change Report 4. 301-312.

Daneshmand, H. and Mahmoudi, P. 2017. Estimation and assessment of temporal stability of periodicities of droughts in Iran. Water Resources Management 31. (11): 3413-3426.

Daneshyar, M.R.M., Bagherzadeh, A. and Khosravi, M. 2013. Assessment of drought hazard impact on wheat cultivation using standardized precipitation index in Iran. Arabian Journal of Geosciences 6. (11): 4463-4473.

Darijani, F., Veisi, H., Liaghati, H., Nazari, M.R. and Kнознвакнт, K. 2019. Assessment of resilience of pistachio agroecosystems in Rafsanjan Plain in Iran. Sustainability 11. (6): 1656.

Dashtpagerdi, M.M., Kousari, M.R., Vagharfard, H., Ghonchepour, D., Hosseini, M.E. and Ahani, H. 2015. An investigation of drought magnitude trend during 1975-2005 in arid and semi-arid regions of Iran. Environmental Earth Sciences 73. (3): 1231-1244.

Degirmendžić, J. and Kożuchowski, K. 2017. Mediterranean cyclones, the atmospheric moisture content and precipitation in Poland. Geographia Polonica 901. 5-20.

Fazel, N., Berndtsson, R., Uvo, C.B., Madani, K. and KLøve, B. 2018. Regionalization of precipitation characteristics in Iran's Lake Urmia basin. Theoretical and Applied Climatology 132. (1-2): 363-373.

GhaEdI, S. 2019. The variability and trends of monthly maximum wind speed over Iran. IDÔJÁRÁS 4. 521-534.

Ghaedi, S. and Shojaiean, A. 2020. Spatial and temporal variability of precipitation concentration in Iran. Geographica Pannonica 244. 244-251.

GhaedI, S. 2021. Underground spaces: a step towards sustainable development in Khuzestan Province, Iran. Problemy Ekorozwoju 16. (1): 193-200.

Gulácsi, A. and Kovács, F. 2018. Drought monitoring of forest vegetation using MODIS-based normalized difference drought index in Hungary. Hungarian Geographical Bulletin 67. (1): 29-42.

HAo, Z. and Singh, V.P. 2015. Drought characterization from a multivariate perspective: a review. Journal of Hydrology 527. 668-678.

Khajeh, S., Paimozd, S. and Moghaddasi, M. 2017. Assessing the impact of climate changes on hydrological drought based on reservoir performance indices case study: Zayandeh Rud River basin, Iran. Water Resources Management 319. 2595-2610. Available at https://doi.org/10.1007/s11269-017-1642-5

Khoshakhlagh, F., Shakouri Katigari, A., Hadinejad Saboori, S., Farid Mojtahedi, N., Momen Poor, F. and Asadi Oskuee, E. 2016. Trend of the Caspian Sea surface temperature changes. Natural Environment Change 2. (1): 57-66.

Lengyel, A. and BottA-Dukát, Z. 2019. Silhouette width using generalized mean - A flexible method for assessing clustering efficiency. Ecology and Evolution 9. (23): 13231-13243.

McKee, T.B., Doesken, N.J. and Kleist, J. 1993. The relationship of drought frequency and duration to time scales. Applied Climatology 17. (22): 179-183.

Modarres, R., Sarhadi, A. and Burn, D.H. 2016. Changes of extreme drought and flood events in Iran. Global and Planetary Change 144. 67-81.

Moghbeli, A., Delbari, M. and Amiri, M. 2020. Application of a standardized precipitation index for mapping drought severity in an arid climate region, south-eastern Iran. Arabian Journal of Geosciences 13. (5): 1-16.

NajAfi, M.R. and Moazami, S. 2016. Trends in total precipitation and magnitude-frequency of extreme precipitation in Iran, 1969-2009. International Journal of Climatology 36. (4): 1863-1872.

Nouri, M. and Homaee, M. 2020. Drought trend, frequency and extremity across a wide range of climates over Iran. Meteorological Applications 27. (2): e1899.

Rostamian, R., Eslamian, S. and Farzaneh, M.R. 2013. Application of standardized precipitation index for predicting meteorological drought intensity in Beheshtabad watershed, central Iran. International Journal of Hydrology Science and Technology 3. (1): 63-76.

Sharafi, L., Zarafshani, K., Keshavarz, M., Azadi, H. and van PAssel, S. 2020. Drought risk assessment: towards drought early warning system and sustainable environment in western Iran. Ecological Indicators 114. (106276): 1-12.

Some'e, B.S., Ezani, A. and Taвari, H. 2012. Spatiotemporal trends and change point of precipitation in Iran. Atmospheric Research 113. 1-12.

SomorowsKa, U. 2017. Soil water storage in Poland over the years 2000-2015 in response to precipitation variability as retrieved from GLDAS Noah simulations. Geographia Polonica 90. (1): 53-64.

Szabó, S., Szopos, N.M., Bertalan-Balázs, B., LÁszló, E., Milošević, D.D., Conoscenti, C. and LÁzÁr, I. 2019. Geospatial analysis of drought tendencies in the Carpathians as reflected in a 50-year time series. Hungarian Geographical Bulletin 68. (3): 269-282.

Tabari, H., Abghari, H. and Hosseinzadeh Talaee, P. 2012. Temporal trends and spatial characteristics of drought and rainfall in arid and semi-arid regions of Iran. Hydrological Processes 26. (22): 3351-3361.

Zarei, A.R., Moghimi, M.M. and Mahmoudi, M.R. 2016. Analysis of changes in spatial pattern of drought using RDI index in south of Iran. Water Resources Management 30. (11): 3723-3743.

ZareI, A.R. 2018. Evaluation of drought condition in arid and semi-arid regions, using RDI index. Water Resources Management 32. 1689-1711.

ZAREI, A.R. and MAsoudi, M. 2019. Trend assessment of climate changes in Iran. EQA-International Journal of Environmental Quality 34. 1-16. 